\title{
Diversity and Biological Activities of Endophytic Fungi Associated with Micropropagated Medicinal Plant Echinacea purpurea (L.) Moench
}

\author{
Luiz H. Rosa ${ }^{1}$, Nurhayat Tabanca ${ }^{2}$, Natascha Techen ${ }^{2}$, David E. Wedge ${ }^{3}$, Zhiqiang Pan ${ }^{3}$, \\ Ulrich R. Bernier ${ }^{4}$, James J. Becnel ${ }^{4}$, Natasha M. Agramonte ${ }^{4}$, Larry A. Walker ${ }^{2}$, Rita M. Moraes ${ }^{2,5}$ \\ ${ }^{1}$ Departamento de Microbiologia, Instituto de Ciências Biológicas, Universidade Federal de Minas Gerais, Minas Gerais, Brazil; \\ ${ }^{2}$ National Center for Natural Products Research, Research Institute of Pharmaceutical Sciences, School of Pharmacy, University of \\ Mississippi, Oxford, USA; ${ }^{3}$ USDA-ARS, Natural Products Utilization Research Unit (NPURU), University of Mississippi, Oxford, \\ USA; ${ }^{4}$ USDA-ARS, Center for Medical, Agricultural, and Veterinary Entomology (CMAVE), Gainesville, USA; ${ }^{5}$ Center for Water \\ and Wetland Resources, The University of Mississippi Field Station, Abbeville, USA.
}

Email: lhrosa@icb.ufmg.br, rmoraes@olemiss.edu

Received June $22^{\text {nd }}, 2012$; revised July $18^{\text {th }}, 2012$; accepted July $29^{\text {th }}, 2012$

\begin{abstract}
Echinacea is one of the top ten selling medicinal herbs in Europe and United States. Commercially available formulations may contain different plant parts of three species (Echinacea purpurea, E. pallida, and E. angustifolia). Our study evaluates the diversity of microbial community associated with healthy E. purpurea clones and their ability to produce defense compounds. We recovered and identified thirty-nine fungal endophytes through the molecular methods in 15 distinct phylotypes, which were closely related to species of the following genera Ceratobasidium, Cladosporium Colletotrichum, Fusarium, Glomerella, and Mycoleptodiscus. These taxa were previously reported as decomposer and phytopathogenic fungi. The fungal community associated with two E. purpurea clones showed high richness and dominance indices with different distribution among plant organs. Crude extracts of fungal isolates were tested for antifungal and insecticidal biological activities. A total of 16 extracts (41\%) showed antifungal properties; while just the extract of $M$. indicus exhibited larvicidal activity against $A$. aegypti. These results suggest that the symbiosis between the endophytic fungal community and micropropagated clones of E. purpurea was re-established after acclimatization to soil and the endophytic fungi produced compounds against phytopathogenic fungi.
\end{abstract}

Keywords: Endophytes; Biological Activity; Medicinal Plant; Symbiosis; Botanical Drug; Microorganisms

\section{Introduction}

The role of symbiosis between plant and microorganism is considered a key element for eukaryotes colonization of the land [1]. Endophytic fungi have been recovered from healthy tissues of plant species growing in different biomes such as tundra, dry deserts, and tropical rainforests from the Arctic to Antarctica. These symbionts produce metabolites that influence plant defense against disease, prevent herbivores' attack, while enhance growth aiding the host's survival under stressful conditions [2]. There are limited information on symbiotic relationship between plants and endophytes to fully understand these types of interactions. According to Taylor et al. [3], plants removed from natural habitat are more susceptible to pathogens attack due to a reduction of endophytes colonization.

Various studies have demonstrated that the endophytic fungal communities associated with medicinal plants produce several bioactive compounds with different biological activities such as antimicrobial, cytotoxic, immunesuppressive and anti-parasitic to protect the host [46]. Echinacea is the second top-selling botanical supplement in the US market due to immune modulator properties [7]. Moraes et al. [8] established an in vitro repository of Echinacea sp. to produce healthy plants in an effort to identify the active constituents responsible for the immune enhancing activities. Pugh et al. [7] reported differences in immune enhancing activities of Echinacea shoot cultures, and later they demonstrated that monocyte and macrophage immune activation is due to lipoproteins and lipopolysaccharides (LPS) of bacterial endophytes. Lata et al. [9] detected endophytes associated with in vitro shoot cultures, which were identified as IAA producing bacteria. To further study the role of endophytes in association with elite Echinacea purpurea 
plants, we investigated the diversity of fungal endophytes associated with micropropagated clones and their capabilities to produce defence compounds to protect its host against pathogenic fungi and herbivores.

\section{Material and Methods}

\subsection{Echinacea in Vitro Repository}

The North Central Regional Plant Introduction Station (NCRPIS), in Ames, Iowa provided seeds of E. purpurea accession PI631307. All experiments were conducted with shoot cultures obtained from hypocotyl explants. Each germinated seed represented one clone. Seeds were surface disinfected as follows: $1 \% \mathrm{NaOCl}(20 \% \mathrm{v} / \mathrm{v}$ bleach) and $0.1 \%$ Tween 20 for $10 \mathrm{~min}$ followed by washing three times in sterile distilled water prior inoculation on the germination media. Aseptic explant initiated shoots on half strength MS medium [10]. After 10 days, $0.5-1.0 \mathrm{~cm}$ long hypocotyls were taken as explants for the initiation of shoot cultures. Shoots grew on half strength MS salt medium containing $3 \%(\mathrm{w} / \mathrm{v})$ sucrose, $0.8 \%(\mathrm{w} / \mathrm{v})$ agar supplemented with $2.2 \mu \mathrm{M}$ of benzyladenine (BA) per liter. The medium was adjusted to $\mathrm{pH}$ 5.7. Shoot cultures have been maintained for 24 months with transference each 30 days. All cultures were incubated at $25^{\circ} \mathrm{C} \pm 2{ }^{\circ} \mathrm{C}, 16$-hours photoperiod under fluorescent light with a photon flux of $52 \mu \mathrm{mol} \cdot \mathrm{m}^{-2} / \mathrm{s}$.

\subsection{Plantlet Cultivation in Pots Maintained in Greenhouse}

Rooted plantlets of different clones of $E$. purpurea were transferred to a soil substrate composed of a mixture (1:2 v/v) potting soil (Potting Mix Miracle Gro 0.140 .14 0.14) and sand (Garden Basic Play Sand, Sims Bark Co, Tuscumbia, AL). Potted plantlets were maintained under mist-irrigation watering cycle for 1-min every hour during 6 hours period similar to the procedure reported for $E$. pallida and E. angustifolia $[9,11]$. Two selected clones of E. purpurea designated as PUR 02 and PUR 30 were planted in pots maintained for three years. Endophytes were isolated from these clones. Early springs plants were fertilized with cottonseed meal 6-2-1 (The Espoma Co, Millville, NJ).

\subsection{Isolation of the Endophytic Fungi}

Healthy leaves, lateral shoots, and roots of four plants of each clones PUR 02 and PUR 30 maintained in greenhouse were cut into pieces, stored in plastic bags at $10^{\circ} \mathrm{C}$ for no more than 24 hours before isolation of the endophytic fungi. Different plant tissues were subjected to surface sterilisation according to protocols established by Rosa et al. [5]. The fragments were inoculated on Petri plates containing potato dextrose agar (PDA; Sigma/ USA) supplemented with chloramphenicol at $200 \mu \mathrm{g} / \mathrm{ml}$ (Sigma/USA). The plates were incubated at $25^{\circ} \mathrm{C}$ for up to 30 days, and individual colonies were transferred to PDA and stored at $4{ }^{\circ} \mathrm{C}$. The fungal species were submitted to a long-term preservation for future research, thus the mycelial pieces were stored in cryotubes with $30 \%$ sterilized glycerol at $-80^{\circ} \mathrm{C}$.

\subsection{Molecular Identification of Endophytic Fungi}

All endophytic fungi were identified by molecular methods. DNA from endophytic fungi was extracted with DNeasy Plant Mini Kit (Qiagen Inc., Valencia, CA) and used as template in PCR amplifications. The ITS1-5.8S -ITS2 genomic region (ITS) was amplified from genomic DNA using the forward primer ITS1 (5'-tccgtaggtgaacetgcgg-3') and the reverse primer ITS4 (5'-tcctccgcttattgatatgc-3') [12]. PCR amplifications were carried out in $50 \mu \mathrm{l}$ reaction mixture containing $1 \times$ PCR reaction buffer, $0.2 \mathrm{mM}$ dNTP mixture, $0.2 \mu \mathrm{M}$ of each forward and reverse primers, $1.5 \mathrm{mM} \mathrm{MgSO}_{4}$ and $2 \mathrm{U}$ of Platinum Taq DNA Polymerase (Invitrogen, CA). The PCR program consisted of one initial denaturation step at $94^{\circ} \mathrm{C}$ for $3 \mathrm{~min}$ followed by 40 cycles at $94^{\circ} \mathrm{C}$ for $30 \mathrm{sec}, 50^{\circ} \mathrm{C}$ for $30 \mathrm{sec}, 72^{\circ} \mathrm{C}$ for $1: 30 \mathrm{~min}$, with a final extension at $72^{\circ} \mathrm{C}$ for $7 \mathrm{~min}$. PCR were run in an M \& J Research Gradient Cycler PTC-225. After amplification, an aliquot was analyzed by electrophoresis on a $1 \%$ TAE agarose gel, visualized under UV light and PCR products were compared to the molecular size standard $1 \mathrm{~kb}$ plus DNA ladder (Invitrogen, CA). Successfully amplified PCR products were extracted using MinElute PCR Purification Kit (Invitrogen, CA) and sequenced on an automated DNA Sequencer (model ABI 3730XL; Applied Biosystems, Foster City, CA). Consensus sequence data of the endophytic fungi were submitted to the GenBank database (see accession numbers in Table 1). According to Gazis et al. [13] the sequence of ITS regions may fail to recognize some Ascomycota taxa; for this reason, the following preliminary criteria were used to interpret the sequences of the GenBank database: for sequence identities $>98 \%$, the genus and species were accepted; for sequence identities between $95 \%$ and $97 \%$, only the genus was accepted; for sequence identities $<95 \%$, isolates were labelled as unknown species and identified in family, class or order hierarchical levels [14]. However, the phylotypes that displayed identities $<97 \%$ or inconclusive taxonomic level were submitted to phylogenetic inferences, which were estimated using MEGA Version 5.0 [15]. The maximum composite likelihood model was used to estimate evolutionary distance with bootstrap 
Table 1. Isolate code, number of isolates, closest related species, maximum identities, number of bp analyzed, identification, and GenBank accession number of endophytic fungi phylotypes associated with Echinacea purpurea (L.) Moench.

\begin{tabular}{|c|c|c|c|c|c|c|c|}
\hline $\begin{array}{l}{ }^{\mathrm{a}} \mathrm{UM} \\
\text { code }\end{array}$ & ${ }^{\mathrm{b}}$ Part & $\begin{array}{l}\mathrm{N}^{\circ} \text { of } \\
\text { isolates }\end{array}$ & $\begin{array}{c}\text { Closest related species/GenBank accession } \\
\text { number }\end{array}$ & $\begin{array}{l}\text { Maximum } \\
\text { identity (\%) }\end{array}$ & $\begin{array}{l}\mathrm{N}^{\circ} \text { of bp } \\
\text { analyzed }\end{array}$ & Proposed identification & $\begin{array}{c}\text { GenBank } \\
\text { accession } \\
\text { number }\end{array}$ \\
\hline 01 & $\mathrm{~L}$ & 1 & Ceratobasidium sp. [AB286937] & 98 & 1638 & Ceratobasidium sp. & HQ148092 \\
\hline 15 & $\mathrm{~L}$ & 8 & $\begin{array}{l}\text { Cladosporium cladosporioides (Fresen.) } \\
\text { G.A. de Vries [EU935608] }\end{array}$ & 99 & 596 & $\begin{array}{l}\text { Cladosporium } \\
\text { cladosporioides }\end{array}$ & HQ148094 \\
\hline 43 & $\mathrm{~L}$ & 1 & $\begin{array}{l}\text { Colletotrichum gloeosporioides (Penz.) Sacc. } \\
\text { [AJ301979] }\end{array}$ & 97 & 1189 & $\begin{array}{l}\text { Colletotrichum } \\
\text { gloeosporioides }\end{array}$ & HQ148099 \\
\hline 32 & $\mathrm{~L}$ & 6 & C. gloeosporioides [GU810508] & 98 & 598 & C. gloeosporioides & HQ148097 \\
\hline 71 & $\mathrm{R}$ & 1 & $\begin{array}{l}\text { Colletotrichum trifolii Bain \& } \\
\text { Essary [AF451909] }\end{array}$ & 95 & 1196 & C. trifolii & HQ148103 \\
\hline 55 & $\mathrm{R}$ & 1 & Colletotrichum sp. [AB443952] & 99 & 621 & Colletotrichum sp. & HQ148100 \\
\hline 68 & $\mathrm{R}$ & 1 & Fusarium oxysporum Schltdl. [FJ156282] & 100 & 773 & Fusarium oxysporum & HQ148102 \\
\hline 77 & Sh & 4 & F. oxysporum [FJ157216] & 99 & 495 & F. oxysporum & HQ148104 \\
\hline 34 & Sh & 2 & F. oxysporum [FJ824032] & 99 & 509 & F. oxysporum & HQ148098 \\
\hline 16 & $\mathrm{~L}$ & 1 & F. oxysporum [GQ365156] & 92 & 565 & Fusarium sp. & HQ148093 \\
\hline 57 & Sh & 1 & Fusarium solani (Mart.) Sacc. [AB518683] & 98 & 612 & F. solani & HQ148101 \\
\hline 78 & $\mathrm{R}$ & 2 & Fusarium sp. [GQ141219] & 92 & 1462 & F. oxysporum & HQ148105 \\
\hline 90 & $\mathrm{~L}$ & 1 & $\begin{array}{l}\text { Glomerella cingulata (Stoneman) Spauld. } \\
\& \text { H. Schrenk [FJ172237] }\end{array}$ & 95 & 1184 & Glomerella sp. & HQ148106 \\
\hline 28 & $\mathrm{~S}$ & 3 & $\begin{array}{l}\text { Mycoleptodiscus indicus (V.P. Sahni) } \\
\text { B. Sutton [GU220382] }\end{array}$ & 97 & 1034 & Mycoleptodiscus indicus & HQ148095 \\
\hline 29 & $\mathrm{~S}$ & 1 & Pleosporales sp. [DQ092514] & 90 & 1138 & Pleosporales sp. & HQ148096 \\
\hline
\end{tabular}

${ }^{\mathrm{a}} \mathrm{UM}=$ Culture code of endophytic fungi; ${ }^{\mathrm{b}}$ Leaf (L), Steam (S), Shoot (Sh), Root (R), and Tuber (T); ${ }^{\mathrm{c}}$ Maximum identity; ${ }^{\mathrm{e}}$ Fungi.

values calculated from 1000 replicate runs. Information about the fungal taxonomic hierarchical levels follows the databases MycoBank (www.mycobank.org) and Index Fungorum (www.indexfungorum.org).

\subsection{Species Richness and Evenness Spatial Analyses}

For measurement of the species diversity, we used the indexes: 1) Shannon $H=-\sum n i / n \ln (n i / n)$ and 2) Simpson's $=1-\operatorname{sum}\left((n i / n)^{2}\right)$, where $n i$ is the number of individuals of the taxon $i$ and $n$ is the total number of individuals. All results were obtained with $95 \%$ confidence, and the bootstrap values were calculated from 1000 iterations. The index calculations were carried out using the computer programme PAST version 1.90 [16].

\subsection{Cultivation and Extraction of Fungal Cultures}

Five millimeter diameter plugs of each endophytic fungus were place at the center of Petri dishes $(90 \mathrm{~mm}$ diameter), each containing $20 \mathrm{~mL}$ of PDA, and cultured for 13 days at $25^{\circ} \mathrm{C} \pm 2{ }^{\circ} \mathrm{C}$ [17]. The material from the resulting fungal cultures were cut from the each Petri dish and transferred to $50 \mathrm{~mL}$ vials tubes containing $25 \mathrm{~mL}$ of ethanol. After $72 \mathrm{~h}$ at room temperature, the organic phase was decanted and the solvent removed under vacuum centrifugation at $40^{\circ} \mathrm{C}$. An aliquot of the dried extract was dissolved in water/methanol (1:1) in order to prepare a $20 \mathrm{mg} / \mathrm{mL}$ stock solution, which was stored at $-20^{\circ} \mathrm{C}$. A similar extraction procedure was carried out using sterile PDA medium, and the extract obtained was used as a control in the bioassays.

\subsection{Biological Activities}

The phytopathogens Colletotrichum acutatum, C. fragariae, and C. gloeosporioides were used as target species for the antifungal assay. These microorganism were grown on PDA (Difco, Detroit, MI) in $9 \mathrm{~cm}$ Petri dishes and incubated in a growth chamber at $24^{\circ} \mathrm{C} \pm 2{ }^{\circ} \mathrm{C}$ under cool-white fluorescent lights $\left(55 \pm 5 \mu \mathrm{mol} / \mathrm{m}^{2} / \mathrm{s}\right)$ with a $12 \mathrm{~h}$ photoperiod to sporulation. Conidia of three fungal targets were harvested from 7 - 10 day old cultures by flooding plates with $5 \mathrm{~mL}$ of sterile distilled water and dislodging conidia by softly brushing the colonies with an L-shaped plastic rod. Aqueous conidial suspensions were filtered through sterile Miracloth (CalbiochemNovabiochem Corp., La Jolla, CA) to remove mycelia. 
Conidia concentrations were determined photometrically [18] from a standard curve based on absorbance at 625 $\mathrm{nm}$, and suspensions were adjusted with sterile distilled water to a concentration of $1.0 \times 10^{6}$ conidia $/ \mathrm{mL}$. Standard conidial concentrations were determined from a standard curve for each fungal species. Standard turbidity curves were periodically validated using both a Bechman/Coulter Z1 particle counter and hemocytometer counts. Conidial and mycelial growth for microdilution broth experiments were evaluated using a Packard model SpectraCount microplate photometer (Packard Instrument Co., Meriden, CT). All extracts of endophytic fungi were diluted in ethanol and spots at 80 and $160 \mu \mathrm{g}$ applied on the TLC plates. Each plate was subsequently sprayed with a spore suspension $\left(10^{5}\right.$ spores $\left./ \mathrm{mL}\right)$ of the target fungus of interest and incubated in a moisture chamber for 4 days at $26^{\circ} \mathrm{C}$ with a $12 \mathrm{~h}$ photoperiod. Clear zones of fungal growth inhibition on the TLC plate indicated the presence of antifungal activity in each extract. Fungal growth inhibition was evaluated 4 - 5 days after treatment by measuring zone diameters. Antifungal metabolites were readily located on the plates by visually observing clear zones where the active compounds inhibited fungal growth [19]. Spots of the fungicide technical grade benomyl (at $1.16 \mu \mathrm{g}$ ), cyprodinil (at $0.9 \mu \mathrm{g}$ ), azoxystrobin (at $1.61 \mu \mathrm{g}$ ), and captan (at 1.2 $\mu \mathrm{g})$ (Chem Service, Inc. West Chester, PA) diluted in ethanol were used as standard controls. All antifungal assays were performed in triplicate. All endophytic fungi extracts were diluted in acetone to six concentrations varying between 500 to $15.625 \mathrm{ppm}$ and topically applied to individual mosquitoes against Ae. aegypti. The procedure was performed according to description of Tabanca et al. [20].

\section{Results}

Thirty-nine endophytic fungi isolates were recovered, which were closely related to the genera Ceratobasidium, Cladosporium, Colletotrichum, Fusarium, Glomerella, and Mycoleptodiscus (Table 1). Among the fungal community living within E. purpurea, Cladosporium cladosporioides, Colletotrichum gloeosporioides, and Fusarium oxysporum were the most abundant phylotypes, while Ceratobasidium sp., Colletotrichum trifolii, Fusarium solani, Glomerella sp., and Pleosporales sp. Represented the scarce phylotypes within this community.

The phylogenetic trees of six phylotypes were constructed to illustrate the relationship of individual sequences to the closest relatives retrieved from GenBank database. The ITS sequence of phylotype UM01 displayed a sequence identity of $>96 \%$ to several sequences: 98\% to Ceratobasidium sp. (AB286937), 98\% to fungal endophyte sp. (FJ613838), 97\% to Thanatephorus сuсumeris (DQ223780), and 96\% to Ceratobasidium cornigerum (EU273525). The sequence alignment (Figure 1(a)) of UM01 with the mentioned before sequences displayed only three nucleotides differences compared to the ITS sequence of Ceratobasidium sp. (AB286937), while more (eight) nucleotides difference were identified when UM01 was compared to the ITS sequence of T. $\mathrm{Cu}$ cumeris (DQ223780). The phylotypes UM16 and UM78 displayed $92 \%$ identities with published ITS sequences of Fusarium oxysporum. In the phylogentic analysis, the phylotype UM16 presented $31(5 \%)$ nucleotides differences to three strains of $F$. oxysporum (GQ365156, FJ605243, and FJ605244). The phylotype UM78 showed $17(2.7 \%)$ nucleotides differences with $F$. oxysporum (HM179532) (Figure 1(b)). The phylotype UM29 displayed identity of $90 \%$ and 78 nucleotide difference (13.6\%) with Pleosporales sp. (DQ092514) and Didymella sp. (DQ092504) (Figure 1(c)). In addition, UM29 presented $\leq 90 \%$ sequence homology with several unidentified and uncultured fungi. The phylotype UM90 showed an identity of $95 \%$ with both the ITS sequence of Glomerella cingulata (FJ172237) and Colletotrichum gloeosporioides (FJ172224). The phylogenetic analysis (Figure 1(d)) of UM90 displayed a 188 difference to $C$. gloeosporioides (FJ172224) and a 189 nucleotide difference to G. cingulata (FJ172237). The phylotype UM55 showed a $100 \%$ nucleotide similarity with different $\mathrm{Co}$ lletotrichum species. However, in the phylogenetic analysis, UM55 showed a high range of sequence identity and only very few nucleotide differences [2 $(0.3 \%)$ to 11 (1.9\%)] (Figure 1(e)) with Colletotrichum sequences. Three endophytes isolates were identified as Mycoleptodiscus indicus UM24, which displayed $97 \%$ of similarity and only five nucleotides difference $(0.8 \%)$ in compareson with different sequences of $M$. indicus deposited in GenBank (Figure 1(f)). A total of four plants per two clones $E$. purpurea were analysed about the associated fungal community, which displayed high diversity (Shannon $H=2.4$ ) and dominance (Simpson's $=0.9$ ). The assemblage composition among the tissues of E. purpurea was variable (Table 1). Only the phylotype $F$. oxysporum occurred in both plant tissues.

A total of $16(41 \%)$ of the 39 endophytic fungi extracts displayed antifungal activity against phytopathogenic Colletotrichum species. Of the 16 endophytic fungi extracts, seven were strongly active against $C$. acutatum, six displayed activity against $C$. fragariae, and eight demonstrated good activity against $C$. gloeosporioides (Table 2). In addition, 10 phylotypes showed extracts with fungicidal activities and six produce a diffuse halo against the Colletotrichum targets. The Fusarium genus was the most active with eight endophytes phylotypes. 


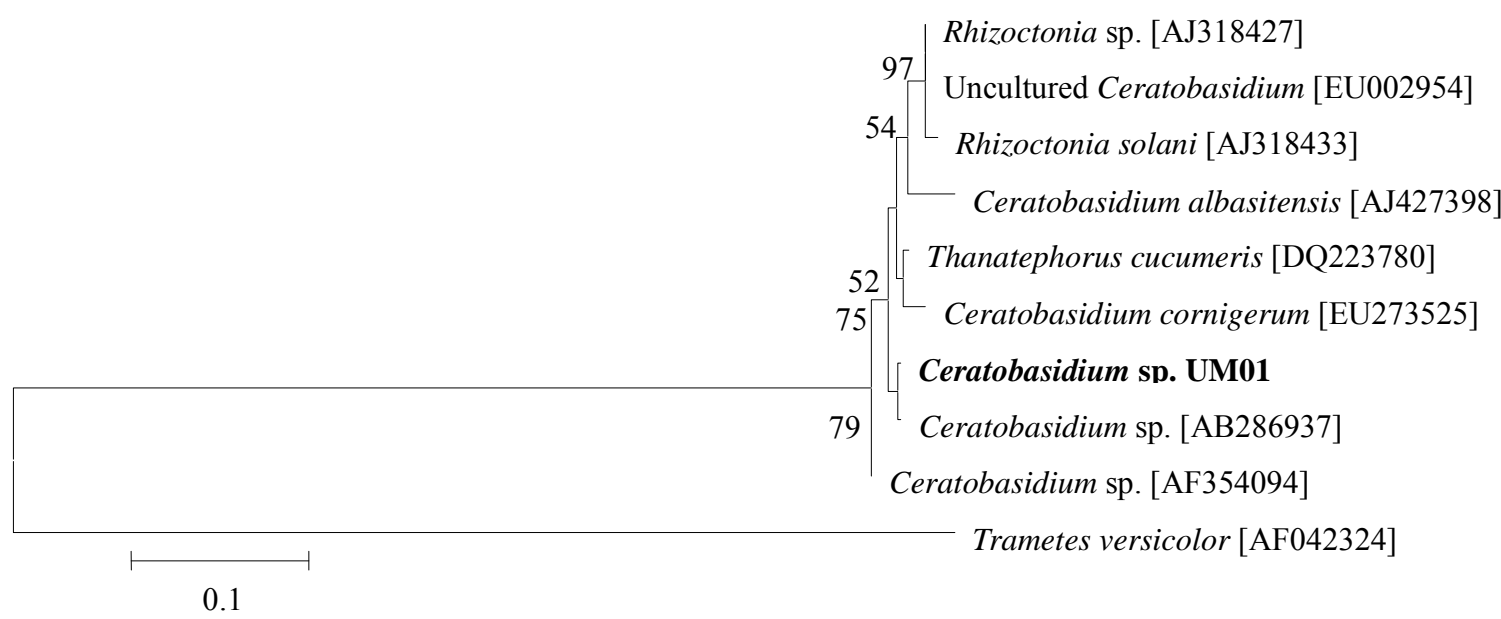

(a)

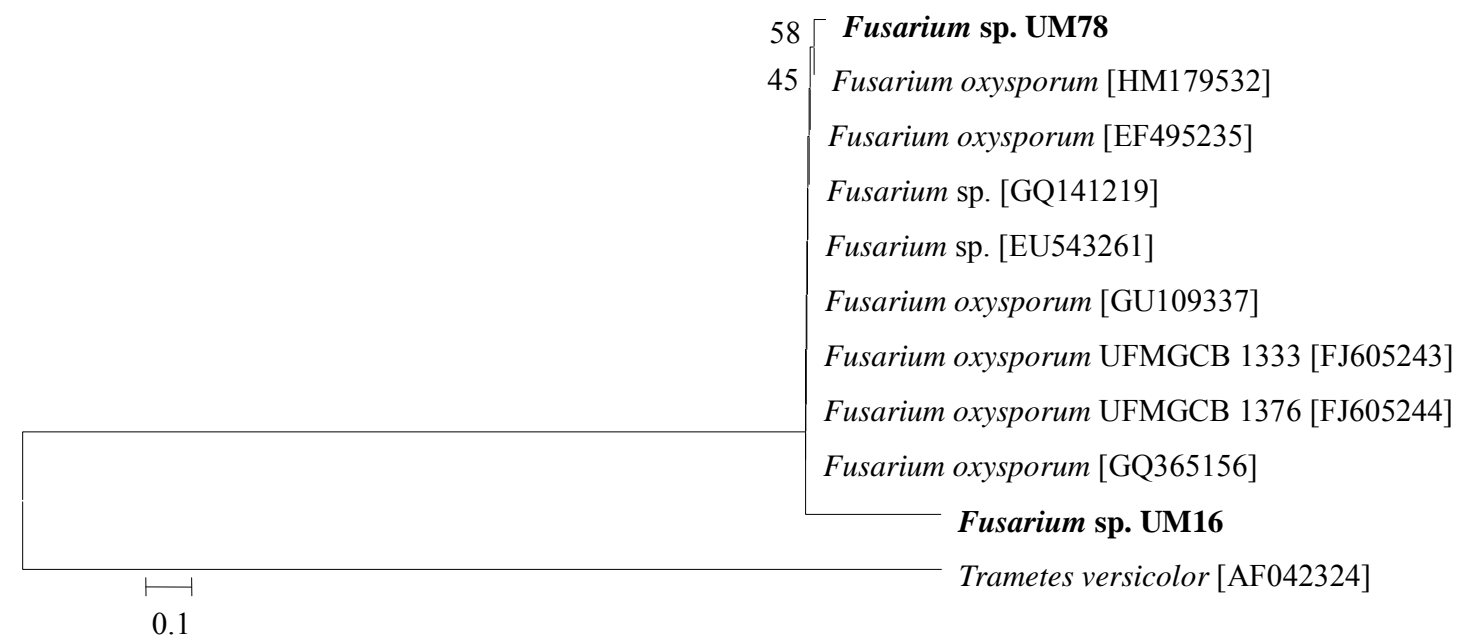

(b)

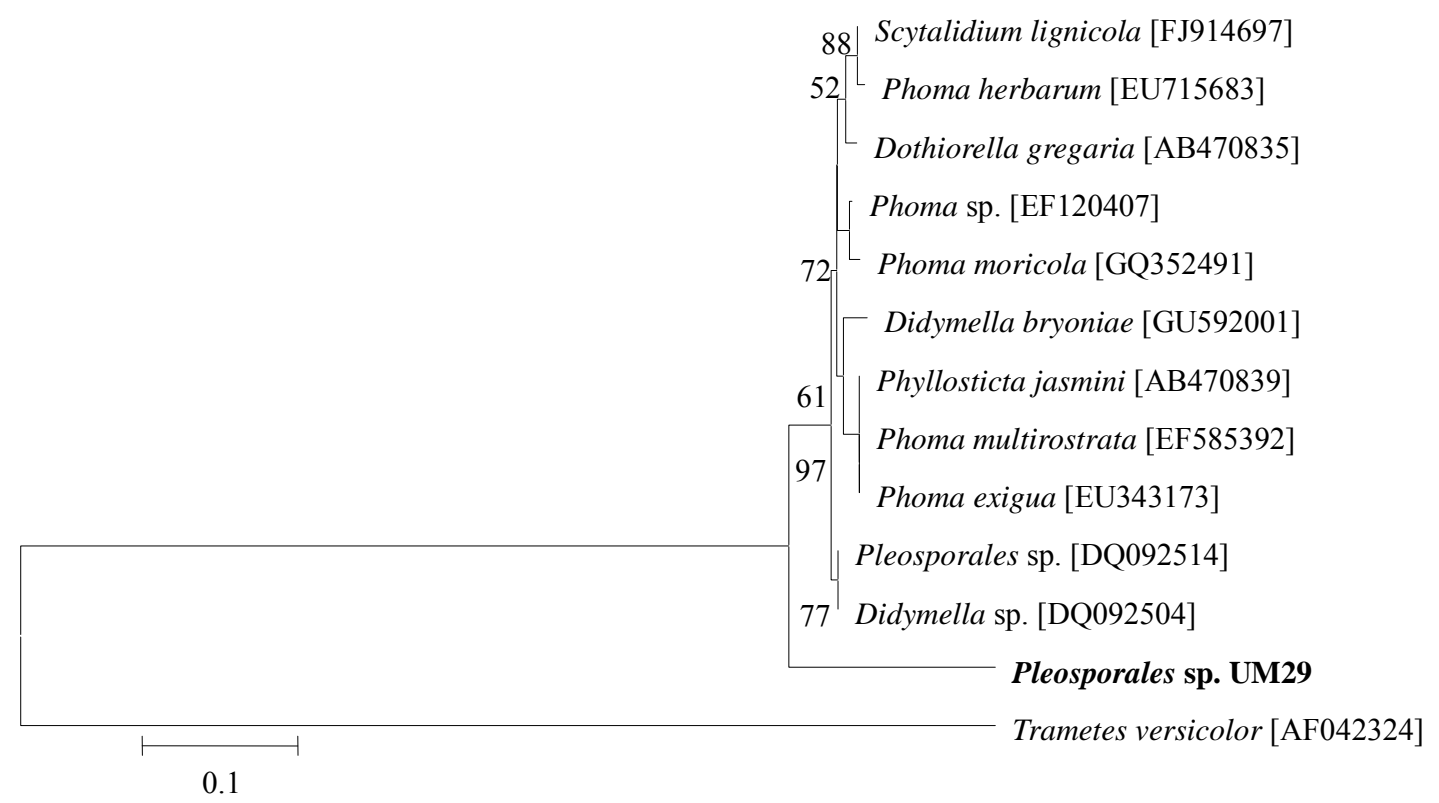

(c) 


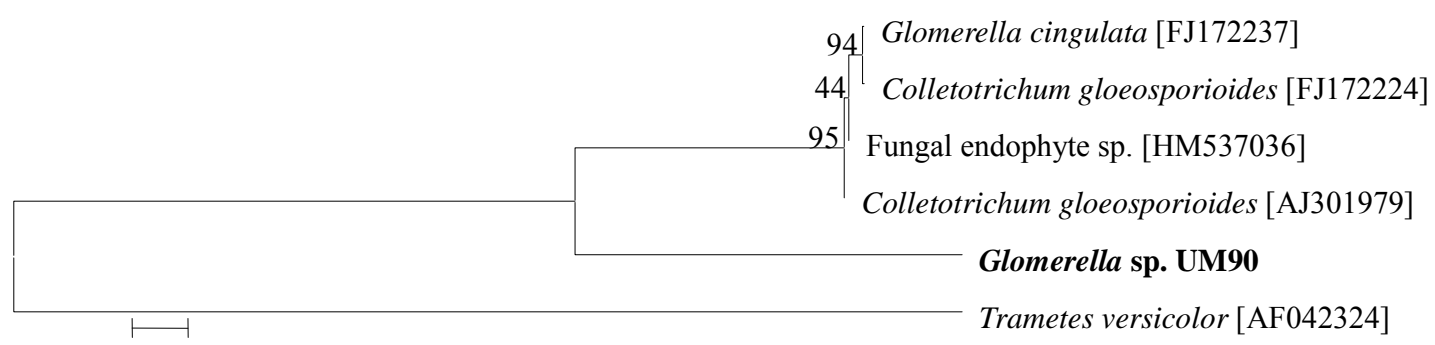

0.1

(d)

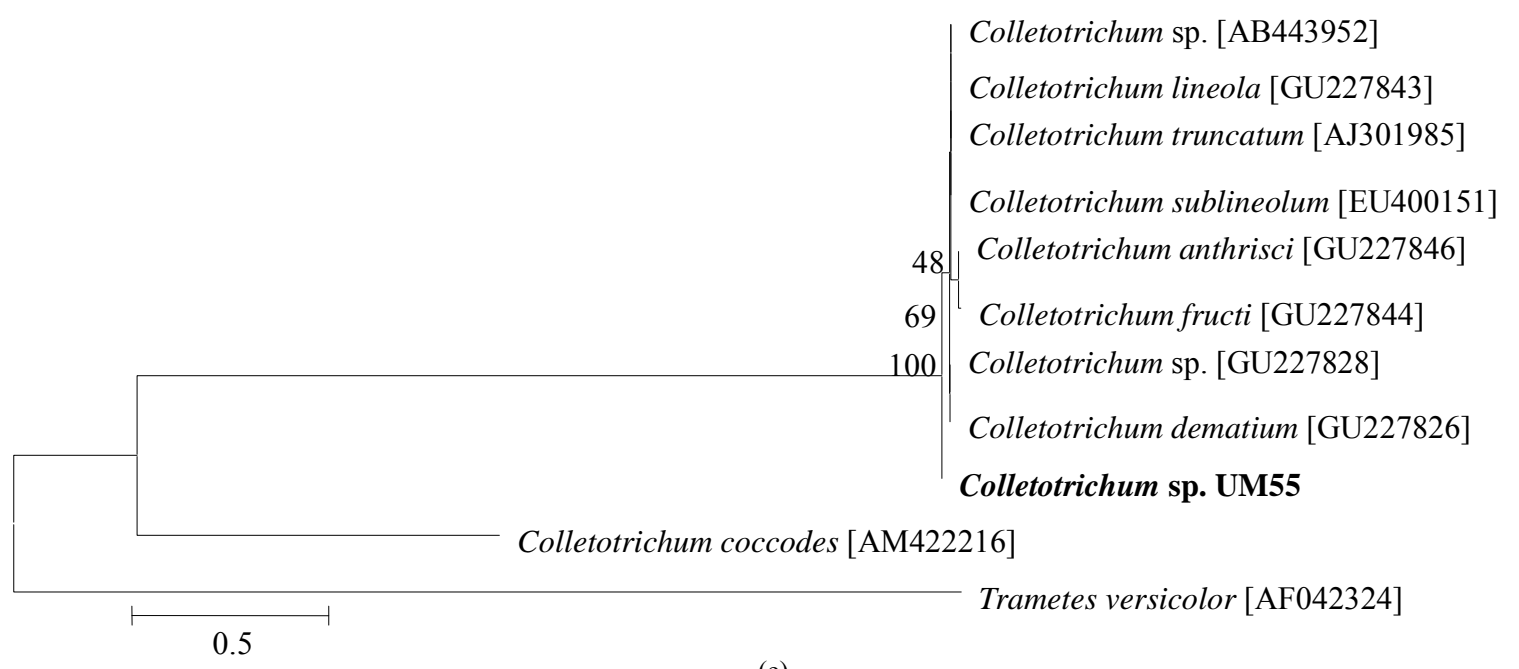

(e)

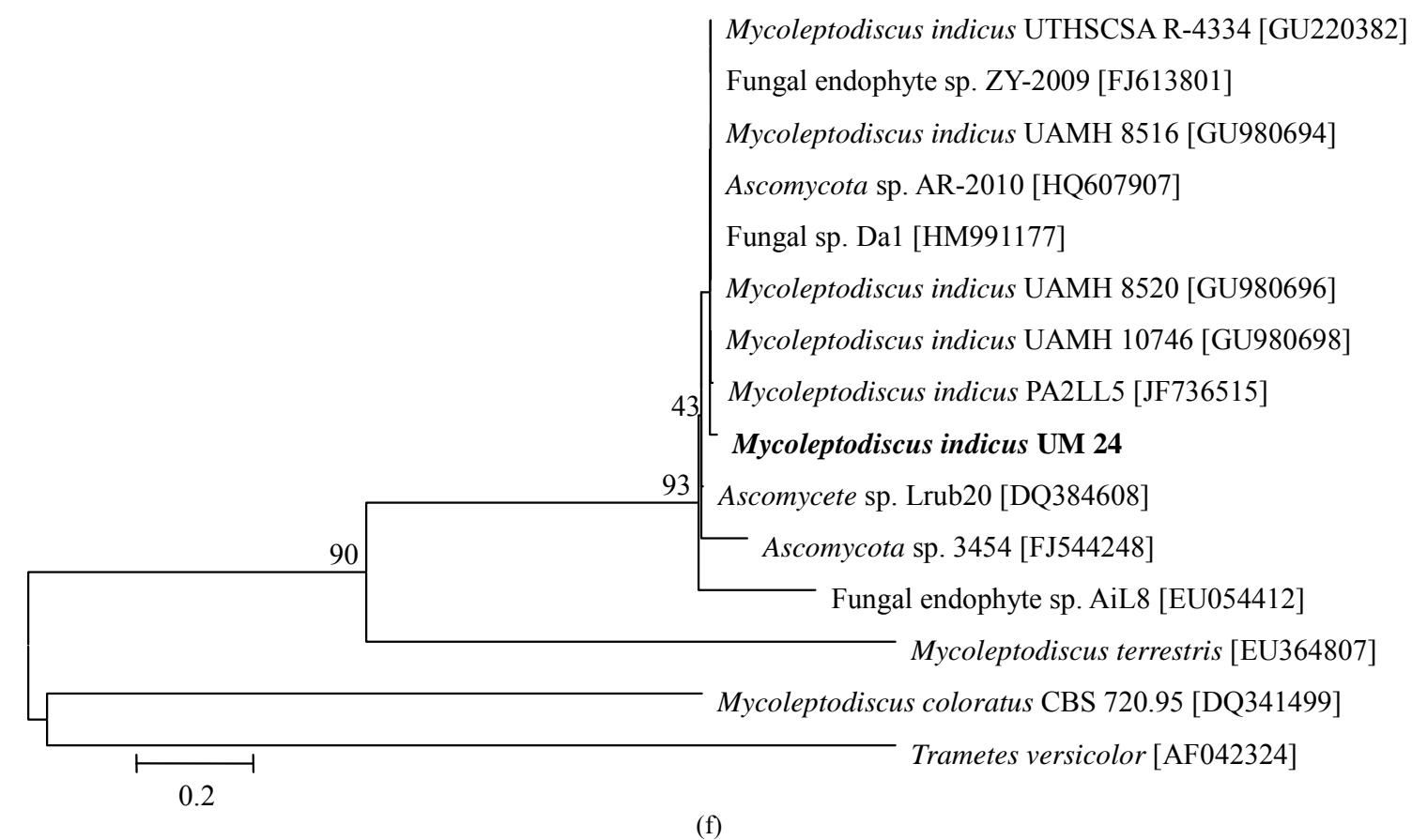

Figure 1. Sequence analyses were performed based on the rRNA gene sequence (ITS1-5.8S-ITS2) using the maximum composite likelihood model to illustrate the relationship of endophytic fungi phylotypes sequences to closest relatives from GenBank BLAST alignments. The tree was rooted with Trametes versicolor (AF042324) as the outgroup. Letters in bold indicate sequences obtained in this study, while other sequences represent reference data obtained from GenBank. 
Table 2. Antifungal activities of crude extracts from endophytic fungi phylotypes isolated from Echinacea purpurea (L.) Moench. using direct bioautography against three Colletotrichum test species.

\begin{tabular}{|c|c|c|c|c|c|c|c|}
\hline \multirow[b]{3}{*}{${ }^{\mathrm{a}} \mathrm{UM}$ code } & \multirow[b]{3}{*}{ Endophytic taxa } & \multicolumn{6}{|c|}{ Mean Fungal Growth Inhibition of Carvacrol $(\mathrm{mm}) \pm \mathrm{SEM}^{\mathrm{b}}$} \\
\hline & & \multicolumn{2}{|c|}{ Colletotrichum acutatum } & \multicolumn{2}{|c|}{ Colletotrichum fragariae } & \multicolumn{2}{|c|}{ Colletotrichum gloeosporioides } \\
\hline & & $80 \mu \mathrm{g} / \mathrm{spot}$ & $160 \mu \mathrm{g} / \mathrm{spot}$ & $80 \mu \mathrm{g} / \mathrm{spot}$ & $160 \mu \mathrm{g} / \mathrm{spot}$ & $80 \mu \mathrm{g} / \mathrm{spot}$ & $160 \mu \mathrm{g} / \mathrm{spot}$ \\
\hline 01 & Ceratobasidium sp. & $\mathrm{d}^{\mathrm{c}}$ & $\mathrm{d}$ & $\mathrm{d}$ & $\mathrm{d}$ & $\mathrm{d}$ & $\mathrm{d}$ \\
\hline 15 & Cladosporium cladosporioides & na & $\mathrm{d}$ & $\mathrm{d}$ & $\mathrm{d}$ & $\mathrm{d}$ & $\mathrm{d}$ \\
\hline 32 & Colletotrichum gloeosporioides & na & na & na & na & na & $\mathrm{d}$ \\
\hline 71 & C. trifolii & $\mathrm{d}$ & $\mathrm{d}$ & $\mathrm{d}$ & $d$ & na & na \\
\hline 55 & Colletotrichum sp. & $\mathrm{d}$ & $\mathrm{d}$ & $\mathrm{d}$ & $\mathrm{d}$ & $\mathrm{d}$ & $\mathrm{d}$ \\
\hline 34 & Fusarium oxysporum & $4.75 \pm 0.8$ & $6.75 \pm 2.2$ & $4 \pm 1.4$ & $5.5 \pm 1.9$ & $2.3 \pm 1.3$ & $1.75 \pm 1.3$ \\
\hline 45 & F. oxysporum & $6.25 \pm 1.5$ & $9.25 \pm 2.2$ & $6.75 \pm 1.41$ & $9 \pm 3.46$ & $6.25 \pm 0.6$ & $8.75 \pm 1.5$ \\
\hline 68 & F. oxysporum & $8 \pm 0$ & $10 \pm 0$ & $5 \pm 0$ & $6 \pm 1.4$ & $5 \pm 0$ & $10.5 \pm 0.7$ \\
\hline 77 & F. oxysporum & $6 \pm 0$ & $9 \pm 0.7$ & $6 \pm 0$ & $8.5 \pm 0.7$ & $4.5 \pm 0.7$ & $8.5 \pm 0.7$ \\
\hline 57 & F. solani & na & na & $\mathrm{d}$ & $\mathrm{d}$ & $\mathrm{d}$ & $\mathrm{d}$ \\
\hline 16 & Fusarium sp. & $7.0 \pm 1.4$ & $10.25 \pm 2.2$ & $\mathrm{~d}$ & $\mathrm{~d}$ & $4.75 \pm 0.7$ & $6.25 \pm 5.7$ \\
\hline 58 & Fusarium sp. & $6 \pm 0$ & $10 \pm 0$ & $5.5 \pm 0.7$ & $9 \pm 0.7$ & $5 \pm 0$ & $7 \pm 0.7$ \\
\hline 78 & Fusarium sp. & $6 \pm 0$ & $10 \pm 0$ & $8 \pm 0$ & $10.5 \pm 0.7$ & $5.5 \pm 0.7$ & $10.5 \pm 0.7$ \\
\hline 24 & Mycoleptodiscus indicus & $\mathrm{d}$ & $\mathrm{d}$ & $\mathrm{d}$ & $\mathrm{d}$ & $7.5 \pm 3.56$ & $9 \pm 5.74$ \\
\hline 28 & M. indicus & na & na & $\mathrm{d}$ & $5 \pm 0$ & na & $\mathrm{d}$ \\
\hline \multirow[t]{5}{*}{29} & Pleosporales sp. & na & na & na & $\mathrm{d}$ & $\mathrm{d}$ & $\mathrm{d}$ \\
\hline & dbenomyl & - & d & - & $19.5 \pm 3.1$ & - & $\mathrm{d}$ \\
\hline & d captan & - & $13.50 \pm 1.9$ & - & $14.25 \pm 2.2$ & - & $16.25 \pm 1.8$ \\
\hline & dcyprodinil & - & d & - & $25 \pm 1.4$ & - & d \\
\hline & ${ }^{\mathrm{d}}$ azoxystrobin & - & $\mathrm{d}$ & - & $26 \pm 1.4$ & - & $\mathrm{d}$ \\
\hline
\end{tabular}

${ }^{a} \mathrm{UM}=$ Culture code of Endophytic fungi; ${ }^{b}$ Mean inhibitory clear zones and standard errors were used to determine the level of antifungal activity against each fungal species; ${ }^{\mathrm{c}} \mathrm{d}=$ Diffuse inhibitory zone. na = no activity. - = no tested; ${ }^{\mathrm{d}}$ Technical grade agrochemical fungicides (without formulation) with different modes of action were used as internal standards (benomyl at $1.16 \mu \mathrm{g}$, captan at $1.2 \mu \mathrm{g}$, cyprodinil at $0.9 \mu \mathrm{g}$, azoxystrobin at $1.61 \mu \mathrm{g}$ ).

The Fusarium extracts were able to inhibit all Colletotrichum targets. Four F. oxysporum distinct isolates and two Fusarium sp. (isolates UM16 and UM78) showed a broad antifungal activities range of $1.75-0.5$ and 4.75 $10.5 \mu \mathrm{g} \cdot \operatorname{spot}^{-1}$, respectively. Selective fungicidal activity against C. gloeosporioides was noticed using the crude extract of phylotype Mycoleptodiscus indicus. This extract also showed a diffuse halo against $C$. acutatum and C. fragariae. In contrast, the extracts of phylotypes Ceratobasidium sp., C. cladosporioides, C. trifolii, Colletotrichum sp., Phomopsis sp., and Pleosporales sp. showed diffuse zones against the Colletotrichum targets (Table 2). Diffuse inhibitory zones are regions on the bioautography plate where fungal growth is visually reduced and interspersed with few mycelia and reproducetive structures and are often characteristic of metabolites from plant, invertebrate, or microorganisms that are moderate suppressive of fungal growth. Most importantly, these fungal extracts displayed antifungal activities similar to commercial agrochemical fungicides benomyl, captan, cyprodinil, and azoxystrobin used as control drugs with halos showing almost the same diameter. Additionally, the extract of phylotype $M$. indicus UM28 showed 100 and $20 \%$ mortality at the concentrations of 125 and $62.5 \mathrm{ppm}$, respectively, against larvae of A. aegypti.

\section{Discussion}

The isolates were identified by molecular tools using the sequencing of the ITS region between the rRNA genes 18S and 26S with sequence length between 495 and 1638 bp. The phylotypes C. cladosporioides, C. gloeosporioides, C. trifolii, F. oxysporum, F. solani, and M. indicus had sequences closely related to the sequences that are deposited in the GenBank database. According to Zalar et al. [21], members of the Cladosporium genus are 
distributed worldwide and C. cladosporioides is one of the most common endophyte species found in association with various plant species. The genus Colletotrichum includes several morphologically similar taxa and can be found as phytopathogenic, saprophytic, and endophytic species [22]. Similar findings have been reported for the species of the genus Fusarium, which was reported as endophytes symbionts associated with orchids [23] and angiosperms [5].

An interesting isolate found in E. purpurea was the phylotype $M$. indicus, a tropical to subtropical species, which generally cause necrosis on leaves of many monocotyledonous plants [24]. In addition to be an agent of leaf necrosis, $M$. indicus have been described as a human pathogen causing subcutaneous phaeohyphomycosis [25]. The sequence of UM24 M. indicus was phylogenetically close to sequences of M. indicus (GU980694, GU980696, and GU980698) described as agent of subcutaneous infection in a dog [26]. Although few studies have indicated that endophytic fungi might be quiescent saprobes or latent pathogens, specific examples detailing these hypotheses remain scant. To our knowledge, this is the first work in which $M$. indicus was isolated as endosymbiont from health leaves of E. purpurea.

Six endophytic phylotypes (UM01, UM16, UM29, UM55, UM78, and UM90) were analyzed for phylogenetic affinities. The genus Ceratobasidium (Basidiomycota) is cosmopolitan being found as saprotrophic, pathogenic and as part of an orchid endomycorrhizal group [27]. Ceratorhiza is the anamorphic genus Ceratobasidium, its species are common endophytes associated with orchids [27]. Glomerella (Ascomycota) is the anamorphic genus Colletotrichum which includes parasites and saprobes species. Species belonging to Glomerella are distributed worldwide and frequently identified as endophytic fungi [28]. The order Pleosporales is the largest in the class Dothideomycetes, and according to Zhang et al. [29] the Pleosporales species can be endo- or epiphytes as parasites on green leaves or stems, saprophytic on dead leaves and stems.

Endophytic assemblages were distributed erratically within the E. purpurea parts. According to Petrini et al. [30], different plant tissues and organs may represent distinct microhabitats and Vieira et al. [6] demonstrated that the composition of endophytic fungal communities associated with medicinal plants vary within tissues. A different finding reported by Summerell and Leslie [31] describes $F$. oxysporum as pathogenic fungus that infects the hosts via root system obstructing the vascular system, thus reducing or preventing the flow of water from the roots to the upper plant, producing wilting symptoms. In this study, $F$. oxysporum was a exception; the fungus was found asymptomatic within in three different tissues of healthy E. purpurea and able to produce extracts with antifungal activity, suggesting a protective symbiosis to the plant.

Fungal extracts of 16 endophytic fungal isolates were active against Colletotrichum targets by inhibiting hyphae's growth and spore germination. Among the isolates are the Cladosporium species, known to produce several secondary metabolites such as cladosporin, emodin, phytase, taxol and antifouling compounds [32] and Fusarium species that synthesize several biologically active metabolites including fusaric acid, moniliformin, fumonisins, zearalenon, enniatins and trichothecenes [33]. The phylotyes $F$. oxysporum UM16 and UM78 showed phylogenetic similarities to two other strains of $F$. oxysporum (FJ605243, FJ605244), recovered from orchid species, Epidendrum secundum and Acianthera teres. Vaz et al. [23] reported that extracts of these F. oxyporum strains had antimicrobial properties against Candida species.

Most of the fungal isolates producing active compounds were associated with plants harvested in their habitats [23,32,33]. According to Taylor et al. [3], the removal of species from their natural environment results in plants more susceptible to attack of different pathogens because disrupt specific or coevolved endophytic communities. Our results demonstrated differently since a highly diverse fungal community was removed from two in vitro propagated clones derived from single $E$. purpurea accession (PI631307). The high numbers of isolates associated with this restricted population indicate that soil and perhaps organic fertilizer (cotton seed meal) were the source of inoculums, and healthy plants produced by tissue culture were able to adapt and acquire their endophytic population. This fungal community presented high dominance index of generalist endophytic fungi, which were also found in high abundance among different plant species [34]. The generalist endophytic fungi in E. purpurea were the phylotypes C. cladosporioides, $C$. gloeosporioides, and $F$. oxysporum.

To our knowledge, this is the first report of fungal community obtained from $E$. purpurea that include endophytes next to saprobes as well as pathogenic related species with great potential to produce compounds with selective antifungal properties, which may be effective in plant defence and key element for cultivation of high quality medicinal Echinacea. Most importantly, these endophytes were isolated from micropropated plants cultivated in pots and during the process of acclimatization into soil had the community restored.

\section{Acknowledgements}

This work received partial support of the FAPEMIG (process CBB 00044/09) and CNPq (process 200774/ 
2011-5). The authors also thank the USDA, Agricultural Research Service Specific Cooperative Agreement No. 58-6408-7-012 for the research support. The authors thank Ms. J. L. Robertson, Ms. R. Pace, Ms. X. Wang, Mr. N. Newlon, Mr. G. Allen, and Mr. W. Reid for performing biological activities. This study was supported by a grant from the Deployed War-Fighter Protection (DWFP) Research Program and the US Department of Defense through the Armed Forces Pest Management Board (AFPMB).

\section{REFERENCES}

[1] D. S. Heckman, D. M. Geiser, B. R. Eidell, R. L. Stauffer, N. L. Kardos and S. B. Hedges, "Molecular Evidence for the Early Colonization of Land by Fungi and Plants," Science, Vol. 293, No. 5532, 2001, pp. 1129-1133. doi:10.1126/science.1061457

[2] K. Clay and J. Holah, "Fungal Endophyte Symbiosis and Plant Diversity in Successional Fields," Science, Vol. 285, No. 5434, 1999, pp. 1742-1744. doi:10.1126/science.285.5434.1742

[3] J. E. Taylor, K. D. Hyde and E. B. G. Jones, "Endophytic Fungi Associated with Temperate Palm, Trachycarpus fortunei, within and outside Its Natural Geographic Range," New Phytologist, Vol. 142, No. 2, 1999, pp. 335346. doi:10.1046/j.1469-8137.1999.00391.x

[4] S. Phongpaichit, N. Rungjindamai, V. Rukachaisirikul and J. Sakayaroj, "Antimicrobial Activity in Cultures of Endophytic Fungi Isolated from Garcinia Species," FEMS Immunology \& Medical Microbiology, Vol. 48, No. 3, 2006, pp. 367-372.

doi:10.1111/j.1574-695X.2006.00155.x

[5] L. H. Rosa, V. N. Gonçalves, R. B. Caligiorne, T. M. A. Alves, A. Rabello, P. A. Sales, A. J. Romanha, M. E. G. Sobral, C. A. Rosa and C. L. Zani, "Leishmanicidal, Trypanocidal, and Cytotoxic Activities of Endophytic Fungi Associated with Bioactive Plants in Brazil," Brazilian Journal of Microbiology, Vol. 41, No. 2, 2010, pp. 420430. doi:10.1590/S1517-83822010000200024

[6] M. L. V. Vieira, A. F. S. Hughes, V. B. Gil, A. B. M. Vaz, T. M. A. Alves, C. L. Zani, C. A. Rosa and L. H. Rosa, "Diversity and Antimicrobial Activities of the Fungal Endophyte Community Associated with the Traditional Brazilian Medicinal Plant Solanum cernuum Vell. (Solanaceae)," Canadian Journal of Microbiology, Vol. 58, No. 1, 2012, pp. 54-66. doi:10.1139/w11-105

[7] N. D. Pugh, P. Balachandran, H. Lata, F. E. Dayan, V. Joshi, E. Bedir, T. Makino, R. Moraes, I. Khan and D. S. Pasco, "Melanin: Dietary Mucosal Immune Modulator from Echinacea and Other Botanical Supplements," International Immunopharmacology, Vol. 5, No. 4, 2005, pp. 637-647. doi:10.1016/j.intimp.2004.12.011

[8] R. M. Moraes, H. Lata, J. Sumyanto, A. M. S. Pereira, B. W. Bertoni, V. C. Joshi, N. D. Pugh, I. A. Khan and D. S. Pasco, "Characterization and Pharmacological Properties of in Vitro Propagated Clones of Echinacea tennesseensis
(Beadle) Small," Plant Cell, Tissue and Organ Culture, Vol. 106, No. 2, 2011, pp. 309-315. doi:10.1007/s11240-011-9922-x

[9] H. Lata, Z. De Andrade, B. Schaneberg, E. Bedir, I. Khan and R. Moraes, "Arbuscular Mycorrhizal Inoculation Enhances Survival Rates and Growth of Micropropagated Plantlets of Echinacea pallid," Planta Medica, Vol. 69, No. 7, 2003, pp. 679-682.

[10] T. Murashige and F. Skoog, "A Revised Medium for Rapid Growth and Bioassays with Tobacco Tissue Cultures," Physiologia Plantarum, Vol. 15, No. 3, 1962, pp. 473-497. doi:10.1111/j.1399-3054.1962.tb08052.x

[11] H. Lata, E. Bedir, I. Khan and R. M. Moraes, "Mass Propagation of Echinacea angustifolia: A Protocol Refinement Using Shoot Encapsulation and Temporary Immersion Bioreactor," Acta Horticulturae, Vol. 629, 2004, pp. 409-414.

[12] T. J. White, T. D. Bruns, S. B. Lee and J. W. Taylor, "Amplification and Direct Sequencing of Fungal Ribosomal RNA Genes for Phylogenetics,” In: N. A. Innis, J. Gelfand and J. Sninsky, Eds., PCR Protocols: A Guide to Methods and Applications, Academic Press, San Diego, 1990, pp. 315-322.

[13] R. Gazis, S. Rehner and P. Chaverri, "Species Delimitation in Fungal Endophyte Diversity Studies and Its Implications in Ecological and Biogeographic Inferences," Molecular Ecology, Vol. 20, No. 14, 2011, pp. 3001-3013. doi:10.1111/j.1365-294X.2011.05110.x

[14] L. H. Rosa, M. de L. A. Vieira, I. F. Santiago and C. A. Rosa, "Endophytic Fungi Community Associated with the Dicotyledonous Plant Colobanthus quitensis (Kunth) Bartl. (Caryophyllaceae) in Antarctica," FEMS Microbiology Ecology, Vol. 73, No. 1, 2010, pp. 178-189.

[15] K. Tamura, D. Peterson, N. Peterson, G. Stecher, M. Nei and S. Kumar, "MEGA5: Molecular Evolutionary Genetics Analysis Using Maximum Likelihood, Evolutionary Distance, and Maximum Parsimony Methods," Molecular Biology and Evolution, Vol. 28, No. 10, 2011, pp. 27312739. doi: $10.1093 / \mathrm{molbev} / \mathrm{msr} 121$

[16] G. S. Ryan, D. A. T. Harper and J. S. Whalley, "PALSTAT, Statistics for Palaeontologist," Chapman \& Hall, London, 1995.

[17] I. F. Santiago, T. M. A. Alves, A. Rabello, P. A. Sales Jr, A. J. Romanha, C. L. Zani, C. A. Rosa and L. H. Rosa, "Leishmanicidal and Antitumoral Activities of Endophytic Fungi Associated with the Antarctic Angiosperms Deschampsia antarctica Desv. and Colobanthus quitensis (Kunth) Bartl.," Extremophiles, Vol. 16, No. 1, 2012, pp. 95-103. doi:10.1007/s00792-011-0409-9

[18] D. E. Wedge and J. M. Kuhajek, "A Microbioassay for Fungicide Discovery," Southern Association of Agricultural Scientists Bulletin, Biochemistry and Biotechnology, Vol. 11, 1998, pp. 1-7.

[19] D. E. Wedge, J. A. Klun, N. Tabanca, et al., "Bioactivity-Guided Fractionation and GC/MS Fingerprinting of Angelica sinensis and Angelica archangelica Root Components for Antifungal and Mosquito Deterrent Activity,' Journal of Agriculture and Food Chemistry, Vol. 57, No. 


$$
\text { 2, 2009, pp. 464-470. }
$$

[20] N. Tabanca, U. R. Bernier, M. Tsikola, et al., "Eupatorium capillifolium Essential Oil: Chemical Composition, Antifungal Activity, and Insecticidal Activity," Natural Products Communication, Vol. 5, No. 9, 2010, pp. 14091415.

[21] P. Zalar, G. S. de Hoog, H.-J. Schroers, P. W. Crous, J. Z. Groenewald and N. Gunde-Cimerman, "Phylogeny and Ecology of the Ubiquitous Saprobe Cladosporium sphaerospermum, with Descriptions of Seven New Species from Hypersaline Environments," Studies in Mycology, Vol. 58, No. 1, 2007, pp. 157-183. doi:10.3114/sim.2007.58.06

[22] D. S. S. Kumar, H. Y. Cheung, C. S. Lau, F. Chen and K. D. Hyde, "In Vitro Studies of Endophytic Fungi from Tripterygium wilfordii with Anti-Proliferative Activity on Human Peripheral Blood Mononuclear Cells," Journal of Ethnopharmacology, Vol. 94, No. 2-3, 2004, pp. 295-300. doi:10.1016/j.jep.2004.05.019

[23] A. B. M. Vaz, M. C. Mota, M. R. Q. Bomfim, et al., "Antimicrobial Activity of Endophytic Fungi Associated with Orchidaceae in Brazil," Canadian Journal of Microbiology, Vol. 55, No. 12, 2009, pp. 1381-1391. doi:10.1139/W09-101

[24] B. C. Sutton, "Pucciniopsis, Mycoleptodiscus and Amerodiscosiella," Transactions of the British Mycological Society, Vol. 60, No. 3, 1973, pp. 525-536. doi:10.1016/S0007-1536(73)80036-1

[25] C. L. Dewar and L. Sigler, "Fungal Arthritis of the Knee Caused by Mycoleptodiscus indicus," Clinical Rheumatology, Vol. 29, No. 9, 2010, pp. 1061-1065. doi:10.1007/s10067-010-1448-9

[26] C. A. Metry, P. S. Hoien-Dalen, C. W. Maddox, et al., "Subcutaneous Mycoleptodiscus indicus Infection in an Immunosuppressed Dog," Journal of Clinical Microbiology, Vol. 48, No. 8, 2010, pp. 3008-3011. doi:10.1128/JCM.02368-09

[27] L. D. Guo, K. D. Hyde and E. C. Y. Liew, "Detection and
Taxonomic Placement of Endophytic Fungi within Frond Tissues of Livistona chinensis Based on rDNA Sequences," Molecular Phylogenetics and Evolution, Vol. 20, No. 1, 2001, pp. 1-13. doi:10.1006/mpev.2001.0942

[28] E. F. Rakotoniriana, F. Munaut, C. Decock, et al., "Endophytic Fungi from Leaves of Centella asiatica: Occurrence and Potential Interactions within Leaves," Antonie van Leeuwenhoek, Vol. 93, No. 1-2, 2008, pp. 27-36. doi:10.1007/s10482-007-9176-0

[29] Y. Zhang, C. L. Schoch, J. Fournier, et al., "Multi-Locus Phylogeny of Pleosporales: A Taxonomic, Ecological and Evolutionary Re-Evaluation," Studies in Mycology, Vol. 64, No. 1, 2009, pp. 85-102. doi:10.3114/sim.2009.64.04

[30] O. Petrini, L. E. Petrini and K. Rodrigues, "Xylariaceaous Endophytes: An Exercise in Biodiversity," Fitopatologia Brasileira, Vol. 20, 1995, pp. 531-539.

[31] B. A. Summerell and J. F. Leslie, "Fifty Years of Fusarium: How Could Nine Species Have Ever Been Enough?" Fungal Diversity, Vol. 50, No. 1, 2011, pp. 135-144. doi:10.1007/s13225-011-0132-y

[32] H. W. Zhang, Y. C. Song and R. X. Tan, "Biology and Chemistry of Endophytes," Natural Products Reports, Vol. 27, No. 5, 2006, pp. 753-771. doi:10.1039/b609472b

[33] F. F. Campos, S. Johann, B. B. Cota, T. M. A. Alves, L. H. Rosa, R. B. Caligiorne, P. S. Cisalpino, C. A. Rosa and C. L. Zani, "Antifungal Activity of Trichothecenes from Fusarium sp. against Clinical Isolates of Paracoccidioides brasiliensis," Mycoses, Vol. 54, No. 4, 2011, pp. e122-e129. doi:10.1111/j.1439-0507.2009.01854.x

[34] L. H. Rosa, M. L. A. Vieira, B. B. Cota, S. Johann, T. M. A. Alves, C. L. Zani and C. A. Rosa, "Endophytic Fungi of Tropical Forests: A Promising Source of Bioactive Prototype Molecules for the Treatment of Neglected Diseases," In: D. Ekinci, Ed., Drug Development-A Case Study Based Insight into Modern Strategies, Intech, Croatia, 2011, pp. 1-18. 